\title{
Prophylaxis/treatment of viral infections in transplant patients
}

LE NICOLLE, MD, FRCPC

T he introduction of effective antiviral therapy has been an important advance in the treatment of infectious diseases in the past 10 years. Initial therapy with vidarabine allowed treatment for herpes simplex virus, and introduction of acyclovir expanded the armamentarium to include varicella-zoster virus. Gancyclovir and, most recently, foscarnet, have expanded the therapeutic armamentarium to include cytomegalovirus (CMV), the most important herpesvirus contributing to morbidity and mortality in transplant recipients. The current challenges in antiviral therapy include determining the most effective use of these agents to provide optimal benefit to the patient and, hopefully, preventing emergence of resistance which may limit effectiveness in therapy in the transplant population. Current experience with and approaches to the use of these antiviral agents is the focus of the third session of this symposium. Dr Preiksaitis reviews current approaches to the management of CMV disease in the solid organ transplant population including donor-recipient matching, CMV safe acellular blood products, passive and active immunization, as well as prophylactic antiviral therapy. She also notes the frustrating paucity of comparative clinical trials providing information to assist in defining the most appropriate treatment options. Dr MacDonald describes the experience of the renal transplant program at Dalhousie University where high dose acyclovir and hyperimmune CMV globulin are used for the prevention of CMV infection. Finally, Dr Rubin discusses the general concepts and significance of herpesvirus infection in the transplant population, and focuses on the management approach of pre-emptive therapy. This approach may prove to be less toxic and more cost effective than the more general use of prophylaxis. All three papers, however, make it clear that well designed and executed clinical studies are still needed to help define and refine our use of antiviral agents in this important and increasing risk population. 


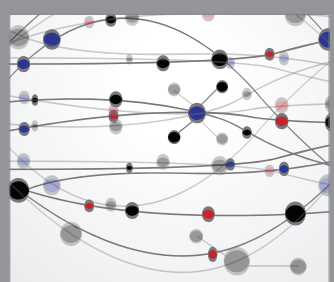

The Scientific World Journal
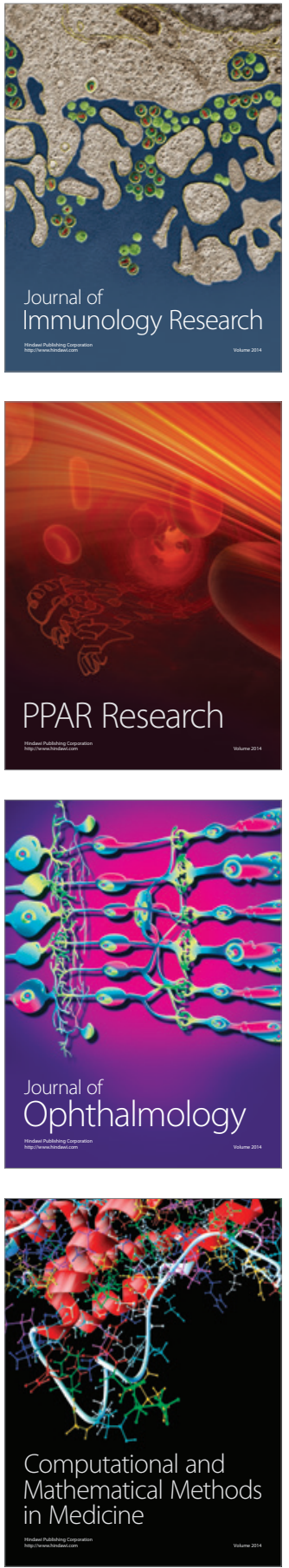

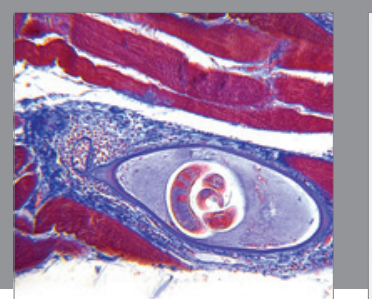

Gastroenterology Research and Practice

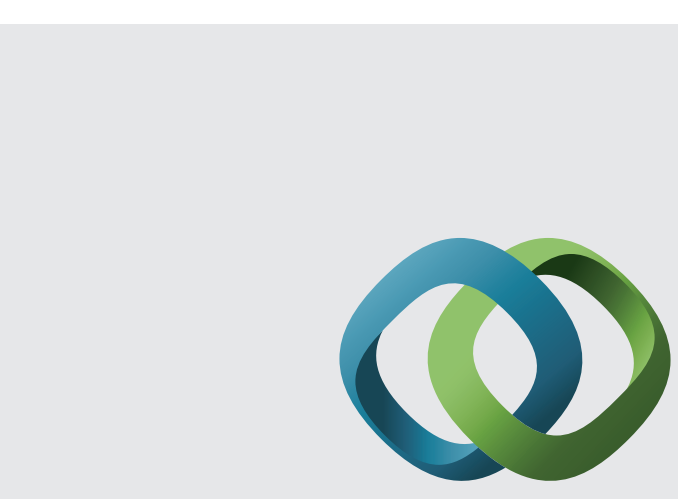

\section{Hindawi}

Submit your manuscripts at

http://www.hindawi.com
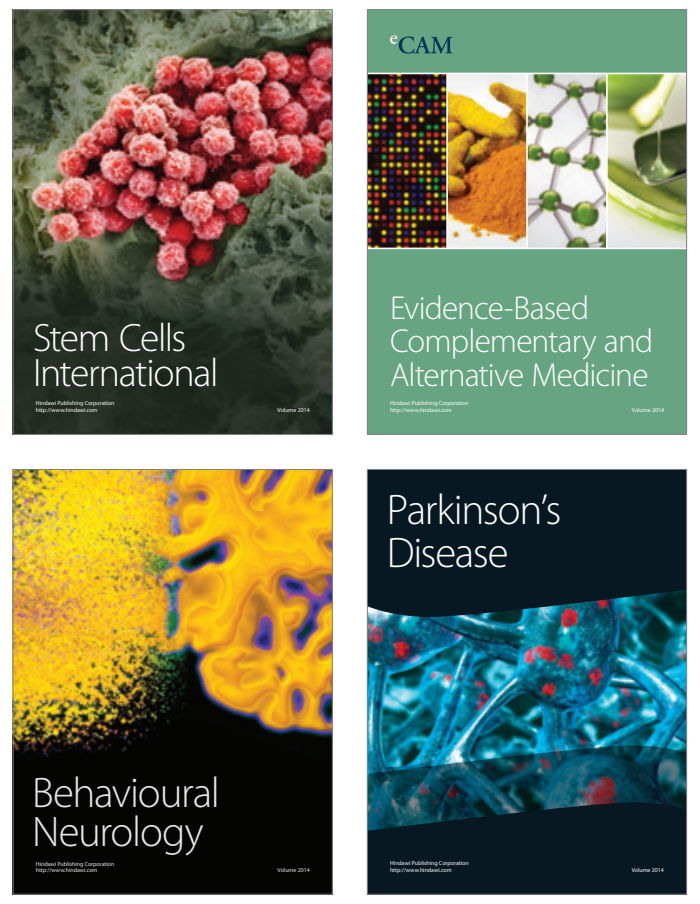
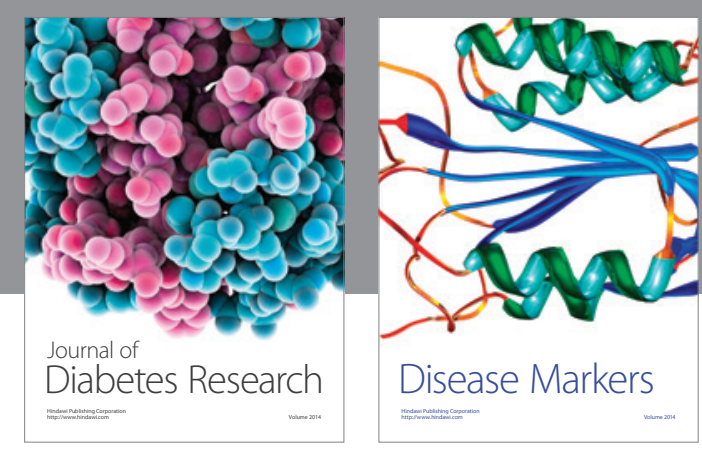

Disease Markers
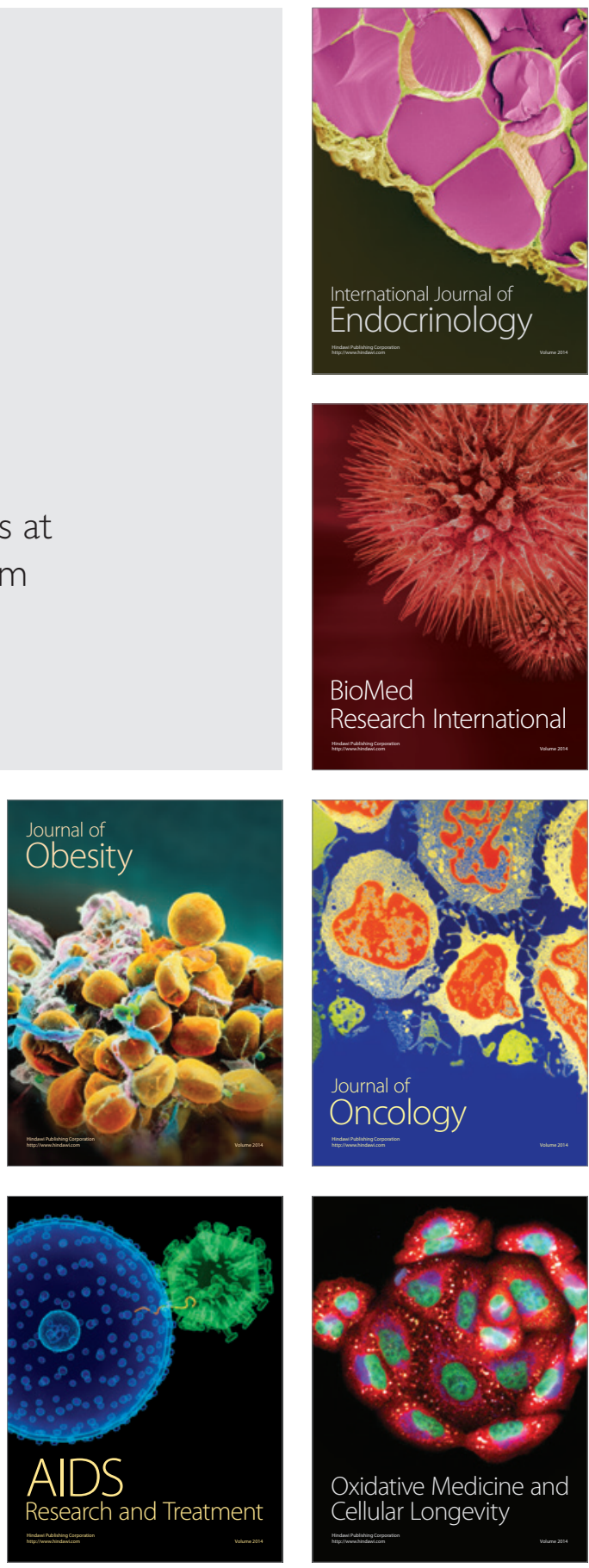